\title{
Prevalence of Hemolysis, Elevated Liver Enzymes, Low Platelet Count Syndrome in Pregnant Women in a Tertiary Care Hospital
}

\author{
Sarita Sitaula, ${ }^{1}$ Tara Manandhar, ${ }^{1}$ Baburam Dixit Thapa, ${ }^{1}$ Ramesh Shrestha, ${ }^{1}$ Dinesh Dharel ${ }^{2}$ \\ 'Department of Obstetrics and Gynecology, BP Koirala Institute of Health Sciences, Dharan, Nepal, ${ }^{2}$ Department of \\ Pediatrics and Department of Community Health and Epidemiology, University of Saskatchewan, Canada.
}

\section{ABSTRACT}

Introduction: Hemolysis, Elevated Liver Enzymes, Low Platelet count syndrome refers to biological syndrome occurring in pre-eclamptic and eclamptic women. There is a higher rate of maternal and perinatal morbidity and mortality due to the syndrome. So, the objective of the study is to find the prevalence and maternal- perinatal outcome in the syndrome.

Methods: A descriptive cross-sectional study was done in a tertiary care hospital from $1^{\text {st }}$ April 2017 to $30^{\text {th }}$ March 2018 after obtaining ethical clearance from the Institutional Review Committee. The inclusion criteria were patients giving consent for participation and those who delivered in our hospital. Patient with the syndrome who delivered outside and referred in the postpartum period was excluded because details of the neonate may not be available. The Statistical Package for Social Sciences version 21 was used for the analysis of the data. Point estimate at 95\% Confidence Interval was calculated along with frequency and proportion for binary data.

Results: Out of 11974 deliveries, the prevalence of Hemolysis, Elevated Liver Enzymes, Low Platelet count syndrome was $83(0.69 \%)$ at 95\% Confidence Interval (59.06-78.94). Maternal complications were seen in 19 (22.9\%) and common complications being acute renal failure 9 (47.37\%) followed by postpartum hemorrhage 4 (21.05\%). Nearly 27 (33\%) of patients required maternal ICU stay and there was one maternal mortality.

Conclusions: Hemolysis, Elevated Liver Enzymes, Low Platelet count syndrome is one of the major causes of maternal and perinatal morbidity and mortality. Hence early recognition and prompt management may improve maternal and fetal outcomes.

Keywords: cesarean section; HELLP syndrome; maternal mortality.

\section{INTRODUCTION}

Hemolysis, Elevated Liver Enzymes, Low Platelet count (HELLP) syndrome is a potentially life-threatening condition manifesting in the context of preeclampsia, which poses challenging diagnostic and management issues to the clinician. ${ }^{1}$ Its incidence is reported as 0.5 $0.9 \%$ of all pregnancies and $10-20 \%$ of women with severe pre-eclampsia ${ }^{2}$ and causes significant mortality and morbidity, which increases with the severity of the syndrome. ${ }^{3}$

This study aims to determine the actual prevalence of
HELLP syndrome and to evaluate the maternal-perinatal outcome associated with it so that early recognition and prompt management may improve maternal and fetal outcomes.

Correspondence: Dr. Sarita Sitaula, Department of Obstetrics and Gynecology, BP Koirala Institute of Health Sciences, Dharan, Nepal. Email: dr.sarita.sitaula@gmail.com, Phone: +9779842052514 
The primary objectives of this study are to find the prevalence

of HELLP syndrome, Maternal outcome (acute kidney injury, abruptio placenta, postpartum haemorrhage, mortality), and Perinatal outcome (Intrauterine Fetal Demise/ Alive, APGAR at 5 minutes, gestational age at delivery). The secondary outcome was the mode of delivery, need of Intensive Care Unit, Neonatal admission rate.

\section{METHODS}

We conducted a descriptive cross-sectional study at the Department of Obstetrics and Gynecology BP Koirala Institute of Health Sciences for one year from $1^{\text {st }}$ April 2017 to $30^{\text {th }}$ March 2018 after obtaining ethical clearance from the Institutional Review Committee of BPKIHS.

The sample size was calculated using the formula,

$$
\begin{aligned}
\mathrm{n} & =\mathrm{Z}^{2} \times(\mathrm{p} \times \mathrm{q}) / \mathrm{e}^{2} \\
& =1.96^{2} \times(0.66 \times 0.34) /(0.132)^{2} \\
& =0.862 / 0.017 \\
& =50.5 \\
& =51
\end{aligned}
$$

where,

$\mathrm{n}=$ required sample size

$\mathrm{p}=$ According to a study done by Abroug et $\mathrm{al}^{4}{ }^{4}$ the prevalence of acute kidney injury in HELLP syndrome was $66 \%$,

$q=1-p$

$\mathrm{e}=$ margin of error, $13.2 \%$

$Z=1.96$ at $95 \%$ Confidence Interval

Adding a non-response rate of $10 \%$ the final sample size was 56 . We enrolled 83 patients with HELLP syndrome during the study period.

The inclusion criteria were patient giving consent for participation and those who delivered in our hospital. Patient with HELLP syndrome who delivered outside and referred in the postpartum period was excluded because details of the neonate may not be available.

Our hospital is a tertiary hospital so many patients with hypertension are referred from another centre. After admission, all hypertensive patients were investigated and managed according to the hospital protocol, and those who met the criteria for HELLP syndrome and meeting inclusion criteria were included in the study.

According to criteria developed at the University of Tennessee, ${ }^{2}$ this syndrome is characterized by the presence of all of the three following criteria: hemolysis (characteristic peripheral blood smear, serum lactate dehydrogenase $\geq 600 \mathrm{U} / \mathrm{l}$, total serum bilirubin $\geq$ $1.2 \mathrm{mg} / \mathrm{dl}$ ), elevated liver enzymes (serum aspartate aminotransferase $\geq 70 \mathrm{U} / \mathrm{l})$, and low platelet count $(<100,000 / \mu l)$. Partial HELLP syndrome (PHS) is defined by the presence of one or two of the criteria. We had diagnosed HELLP syndrome according to these criteria. They were followed up till the discharge from the hospital and maternal and perinatal outcomes were recorded in the proforma.

Abruptio placenta was diagnosed by clinical assessment ${ }^{5}$ with complaints of vaginal bleeding, abdominal pain, hypotension, increased tone, or retroplacental clots during delivery of the placenta. Postpartum haemorrhage was defined as a blood loss of $500 \mathrm{ml}$ or more within 24 hours after birth according to WHO. ${ }^{6}$ Acute kidney injury was diagnosed according to the $\mathrm{AKIN}^{7,8}$ criteria which are defined as Abrupt (within 48 h) reduction in kidney function currently defined as an absolute increase in serum creatinine of $0.3 \mathrm{mg} / \mathrm{dL}$ or more $(\geq 26.4 \mu \mathrm{mol} / \mathrm{L}$ ) or a percentage increase in serum creatinine of $50 \%$ or more (1.5-fold from baseline) or a reduction in urine output (documented oliguria of $<$ $0.5 \mathrm{~mL} / \mathrm{kg} / \mathrm{h}$ for $>6 \mathrm{~h}$ ). Statistical Package for Social Sciences version 21 was used for the analysis of the data and point estimate at $95 \%$ Confidence interval was calculated along with frequency and proportion for binary data and the analysis was done.

\section{RESULTS}

The total number of deliveries within the study period was 11974 and there were 83 patients with HELLP syndrome. Hence, the prevalence of HELLP syndrome was $83(0.69 \%)$ of total deliveries. Out of the 64

\begin{tabular}{|c|c|c|}
\hline $\begin{array}{l}\text { Table 1. Backgrou } \\
\text { population }(n=83) \text {. }\end{array}$ & tics & the study \\
\hline Characteristics & & n (\%) \\
\hline Age & Less than 19 & $16(19)$ \\
\hline & Primigravida & $43(51.8)$ \\
\hline Gravida & Multigravida & $40(48.2)$ \\
\hline & Less than 34 week & $50(60.2)$ \\
\hline Gestational age & $\begin{array}{l}\text { More than } 34 \\
\text { week }\end{array}$ & $33(39.8)$ \\
\hline B $\quad$ o $\quad o \quad k \quad e r d /$ & Booked & $17(20.5)$ \\
\hline unbooked & Unbooked & $66(79.5)$ \\
\hline Gestation & $\begin{array}{l}\text { Singleton } \\
\text { Twin }\end{array}$ & $\begin{array}{l}75(90.36) \\
8(9.64)\end{array}$ \\
\hline
\end{tabular}
$(77.1 \%)$ had partial and $19(22.9 \%)$ had complete HELLP syndrome.

Table 1 shows the general variables of the study population (Table 1). 
Similarly $27(32.5 \%)$ mothers required ICU stay, 56 $(67.5 \%)$ did not. $22(26.5 \%)$ required blood transfusion. One (1.2\%) patient expired (Table 2).

\begin{tabular}{|c|c|c|}
\hline Outcome & & n (\%) \\
\hline \multirow{3}{*}{ Mode of delivery } & Vaginal delivery & $38(45.8)$ \\
\hline & Cesarean section & $43(51.8)$ \\
\hline & Vacuum delivery & $2(2.4)$ \\
\hline \multirow{2}{*}{ ICU* stay } & Required & $27(32.5)$ \\
\hline & Not required & $56(67.5)$ \\
\hline \multirow{2}{*}{ Blood transfusion } & Required & $22(26.5)$ \\
\hline & Not required & $61(73.5)$ \\
\hline \multirow[t]{4}{*}{ At discharge } & Improved & $80(96.4)$ \\
\hline & Discharge on request & $1(1.2)$ \\
\hline & $\begin{array}{l}\text { Leaving against } \\
\text { medical advice }\end{array}$ & $1(1.2)$ \\
\hline & Expired & $1(1.2)$ \\
\hline
\end{tabular}

*ICU: Intensive Care Unit

Nine $(47.37 \%)$ mothers had acute renal failure, 2 $(10.53 \%)$ had abruptio placenta, 3 (15.79\%) had pulmonary oedema and $4(21.05 \%)$ had postpartum haemorrhage (Table 3).

\begin{tabular}{|lc|}
\hline \multicolumn{2}{|l|}{ Table 3. Maternal complications. } \\
\hline Complications & $\mathbf{n}(\%)$ \\
Acute renal failure & $9(47.37)$ \\
Abruptio placenta & $2(10.53)$ \\
Pulmonary oedema & $3(15.79)$ \\
Postpartum haemorrhage & $4(21.05)$ \\
Retinopathy & $2(10.53)$ \\
Continuous seizure & $1(5.26)$ \\
\hline *One patient had developed both abruption and \\
postpartum haemorrhage and another one had both \\
postpartum haemorrhage and acute renal failure
\end{tabular}

Eighty $(87.9 \%)$ survival and $11(12.09 \%)$ Intrauterine fetal death was seen (Table 4).

\begin{tabular}{|ll|}
\hline \multicolumn{2}{|l|}{ Table 4. Perinatal outcomes. $(\mathbf{n}=\mathbf{9 1})$} \\
\hline Variables & $\mathbf{n}(\%)$ \\
Alive & $80(87.9)$ \\
IUFD & $11(12.09)$ \\
\hline
\end{tabular}

Twenty-six (32.5\%) newborn required neonatal admission. And there were $2(2.5 \%)$ neonatal death. The most common cause of neonatal admission was the low birth weight $(53.84 \%)$ followed by respiratory distress $(26.92 \%)$. The mean birth weight was $2199.84 \mathrm{gm} \pm$ 703.46gm. Median APGAR scores at 1 and 5 minutes among live newborns were 7 and 8 respectively.

\section{DISCUSSION}

HELLP syndrome is a life-threatening complication, considered to be a severe variant of hypertension in pregnancy, which is one of the major causes of a higher rate of maternal and perinatal morbidity and mortality. In this study prevalence of HELLP syndrome was 83 $(0.69 \%)$ of total pregnancies which are comparable to the study done by Haram et al. ${ }^{2}$

All women enrolled were in the antenatal period in our study with an average gestational age at presentation being $36.17 \pm 3.55$ weeks. And $60 \%$ of the patient had presented before 34 weeks of gestation. According to a study by Rahman \& Wendon ${ }^{9}$ this disorder is diagnosed antenatally in $70 \%$ of the women. Mean maternal age in our study: $24.84 \pm 5.90$ years which is comparable to the study conducted by Nigar Sadaf et al, i.e, $28.23 \pm 5.9$ years. $^{10}$ It has been shown that maternal mortality decreasing up to $1 \%$ with treatment although complications as placental abruption, acute kidney injury, subcapsular liver hematoma, retinal detachment occur in about $25 \%$ of women.

In this study maternal complications were seen among $22.9 \%$ of the patient and most common being an acute renal failure $(47.37 \%)$ followed by postpartum haemorrhage $(21.05 \%)$. This result is also similar to the study done by Nigar Sadaf et al. ${ }^{10}$ where acute renal failure was the most common maternal complication followed by abruptio placenta. Another study was done by Kestutis et al. ${ }^{11}$ showed placental abruption in $14.7 \%$ of the cases with complete HELLP syndrome. Maternal mortality is as high as $37 \%$ as shown in the study done by P Tiwari et al. which is seen in only $1.2 \%$ of cases in our study. ${ }^{12}$ Less maternal mortality in our study could be due to the enrollment of fewer cases of complete HELLP syndrome (23\%) because morbidity and mortality are more in complete than in partial HELLP syndrome.

In this study, $51.8 \%$ of the patient underwent cesarean section and the most common cause for cesarean was non-reactive fetal heart tracing (44\%) followed by failed induction. Which is similar to other studies done by Nigar Sadaf et al $^{10}$. Perinatal mortality and morbidity are considerably higher in this syndrome and are primarily dependent on the gestational age when the condition develops. The perinatal mortality rate related to HELLP syndrome is between $7.4 \%$ and $34 \% .{ }^{13}$ Perinatal morbidity and mortality are associated with fetal growth restriction, oligohydramnios, non-reassuring fetal heart rate, preterm birth, low birth weight, birth asphyxia, stillbirth, and intrapartum death. And this is believed to be caused by placental insufficiency and generalized endothelial damage. ${ }^{14}$ In our study perinatal death is 
around $15 \%$ and the neonatal admission rate is $28.5 \%$ and a common cause for admission was low birth weight and respiratory distress, which is comparable to the study done by Zen et al. who reported perinatal mortality of $29 \%$ with HELLP syndrome. ${ }^{15} \mathrm{We}$ have enrolled both partial and complete HELLP syndrome patients in this study which might have some influence on the maternal and perinatal outcome. If we would have taken the cases of complete HELLP syndrome result might have been more significant. This is an only descriptive study, it would have been better if we could have compared the findings between HELLP and non HELLP patients among hypertensive disorder.

\section{CONCLUSIONS}

HELLP syndrome is a life-threatening complication of pregnancy, though its incidence is less it is associated with high maternal and perinatal morbidity and mortality. Hence early diagnosis and prompt management are required for the good maternal and perinatal outcome, as the delivery of the fetus is the best way to prevent complications.

\section{Conflict of Interest: None.}

\section{REFERENCES}

1. New York State Department of Health. Hypertensive disorders in pregnancy. 2013 May. [Full Text]

2. Haram K, Svendsen E, Abildgaard U. The HELLP Syndrome: clinical issues and management. A Review. BMC Pregnancy Childbirth. 2009;9:8. [PubMed | Full Text | DOI]

3. Martin JN, Rose $\mathrm{CH}$, Briery $\mathrm{CM}$. Understanding and managing HELLP syndrome: the integral role of aggressive glucocorticoids for mother and child. Am J Obstet Gynecol. 2006;195(4):914-34. [PubMed | Full Text | DOI]

4. Abroug F, Boujdaria R, Nouira S, Abroug, Souissi M, Najjar MF et al. Hellp syndrome: Incidence and maternal-fetal outcome - a prospective study. Intensive Care Med. 1992;18:274-7. [PubMed |Full Text | DOI]

5. Antonette T Dulay. Abruptio Placentae. Merck Manuals Professional Edition. October 2017. [Full Text]

6. WHO recommendations on prevention and treatment of postpartum haemorrhage. 2012. [Full Text]

7. 7. Mehta RL, Kellum JA, Shah SV, et al. Acute Kidney Injury Network: report of an initiative to improve outcomes in acute kidney injury. Crit Care. 2007;11(2):R31. [PubMed | Full Text | DOI]

8. Mehta R, Kellum JA, Levin A. From acute renal failure to acute kidney injury: what's changed? Nephrology SelfAssessment Program.2007;6(5):28. [PubMed | Full Text | DOI

9. Rahman, TM, Wendon J. Severe Hepatic dysfunction in pregnancy. QJM. 2002; 95(6):343-57. [uuMed | Full Text | $\underline{\mathrm{DOI}}]$
10. Sadaf N, Haq G, Shukar-ud-Din S. Maternal and foetal outcome in HELLP syndrome at tertiary care hospital. J Pak Med Assoc. 2013;63(12):1500 $\square$ 3. [PubMed | Full Text]

11. Rimaitis K, Grauslyte L, Zavackiene A, Baliuliene V, Nadisauskiene R, Macas A. Diagnosis of HELLP syndrome: a 10-year survey in a perinatology centre. Int J Environ Res Public Health. 2019;16(1):109. [ubMed | Full Text | DOI]

12. Tiwari P, Bhalavi S, Nayak S, Tiwari R. A Study of HELLP syndrome among cases of pre-eclampsia and eclampsia: incidence and correlation of laboratory parameters. Open Access. 8 September 2015. [Full Text | DOI]

13. Sibai BM. Diagnosis, controversies, and management of the syndrome of hemolysis, elevated liver enzymes, and low platelet count. Obstet Gynecol. 2004;103(5 Pt 1):981ロ91. [PubMed | Full Text | DOI]

14. Gansevoort W, Rep A, de Vries JIP, Bonsel GJ, Wolf $\mathrm{H}$, PETRA-investigators. Prediction of maternal complications and adverse infant outcome at admission for temporizing management of early-onset severe hypertensive disorders of pregnancy. Am J Obstet Gynecol.2006;195(2):495-503. [ PubMed $\mid$ Full Text $\mid \underline{\text { DOI] }}$

15. Zeng F, Chen D. A report of fourteen cases with hemolysis, elevated liver enzymes and low platelet count syndrome. Zhonghua Fu Chan Ke Za Zhi. 2000;37:526-8. [PubMed] 